\title{
Alfabetização informacional desde a infância: apontamentos a partir da pesquisa "TIC Kids Online Brasil"
}

\author{
Information Literacy since childhood: notes from the report "ICT Kids Online \\ Brazil”
}

\section{La Alfabetización Informacional desde la infancia: apuntes a partir de la pesquisa "TIC Niños Online Brasil"}

\author{
Maximiliano Martin Vicente \\ Mayra Fernanda Ferreira ${ }^{2}$
}

\section{Resumo}

O presente trabalho tem como objetivo identificar as competências informacionais das crianças a partir dos usos que fazem da internet. Considerando a emergência de uma geração digital, que se relaciona naturalmente com as tecnologias, é importante analisar os interesses infantis e de que modo as crianças são formadas para fazer um bom uso das informações, isto é, se há um contexto e um processo de alfabetização informacional. Tendo como objeto de análise descritiva e de conteúdo os dados do relatório "TIC Kids Online Brasil 2015", realizado pelo Comitê Gestor da Internet no Brasil, articulando-os com a proposta de Alfabetização Midiática e Informacional da Unesco, verifica-se a necessidade de diretrizes para assegurar o acesso e o uso competente de informações pelas crianças. Ao garantir o acesso e um uso ético, criativo e crítico das informações, acredita-se na contribuição para uma infância ativa e cidadã em uma sociedade democrática.

\begin{tabular}{|c|c|}
\hline \multirow{3}{*}{ 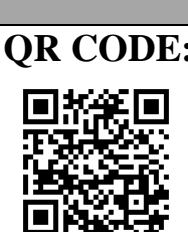 } & Acesse este artigo online \\
\hline & $\begin{array}{l}\text { Website: } \\
\text { http://www.revistas.ufg.br/index.php/ci }\end{array}$ \\
\hline & $\begin{array}{l}\text { DOI: } \\
\text { http://dx.doi.org/10.5216/ci.v20i1.44734 }\end{array}$ \\
\hline
\end{tabular}

Palavras-chave:

Alfabetização informacional. Infância. Tecnologias da informação e da comunicação. Formação infantil. Cidadania.

\footnotetext{
Abstract

The present work aims to identify the children's informational competences from their uses of internet. Having regard of the emerging of a digital generation, that relates naturally with technology, it is important to analyze the children's interests and how they are educated to make good use of information, i.e, if there is a context and an informational alphabetization process. Exploring the "ICT Kids Online Brazil 2015" survey, made by the Brazilian Internet Steering Committee, this paper intents to compare its data with the Media and Information Literacy (MIL - UNESCO) proposal in order to indicate guidelines to children's access and

1 Livre-docente em História. Docente da graduação e pós-graduação da Faculdade de Arquitetura, Artes e Comunicação da Unesp em Bauru. Membro do Grupo de Pesquisa Mídia e Sociedade. Brasil, São Paulo, Bauru. E-mail: maxvicente@faac.unesp.br

2 Doutoranda em Comunicação da Unesp. Mestre em Comunicação e Bacharel em Comunicação Social. Coordenadora e docente do curso de Jornalismo da Universidade do Sagrado Coração. Jornalista da TV Universitária Unesp. Brasil, São Paulo, Bauru. E-mail: mayraunesp@ yahoo.com.br
}

Comun. \& Inf., Goiânia, GO, v. 20, n. 1, p. 42-56, jan./jun. 2017 
uses of the informations. By ensuring the access to information and an ethical, creative and critical use of them, it is expected a contribution to an active and a citizen childhood in a democratic civilization.

Keywords: Information Literacy. Childhood. Information and Communication Technologies. Infant Education. Citizenship.

\section{Resumen}

El siguiente trabajo tiene como objetivo identificar las competencias informacionales de los niños a partir de los usos que hacen del Internet. Considerando una emergente generación digital, que se relaciona naturalmente con las tecnologías, es importante analizar los intereses infantiles y de qué manera los niños son formados para hacer un bueno uso de las informaciones, o sea, si existe uno contexto y uno proceso de alfabetización informacional. Teniendo como objeto de análisis descriptiva y de contenido los datos del informe "TIC Niños Online Brasil 2015”, realizado por el Comité Gestor del Internet en Brasil, articulando esos datos con la propuesta de Alfabetización Mediática y Informacional de la UNESCO, señala la necesidad de directrices para el acceso y uso competente de informaciones. Al garantizar el acceso y un uso ético, creativo y crítico de las informaciones, se cree en la contribución para una infancia activa y civilizada en una sociedad democrática.

Palabras-clave: Alfabetización Informacional. Infancia. Tecnologías de la información y de la comunicación. Formación infantil. Ciudadanía.

\section{INTRODUÇÃO}

"A criança tem direito à liberdade de expressão. Este direito compreende a liberdade de procurar, receber e partilhar informações e ideias de toda a espécie, sem considerações de fronteiras, sob forma oral, escrita, impressa ou artística ou por qualquer outro meio à escolha da criança" (ONU, 1989, artigo 13). Essa é uma das defesas da Convenção das Nações Unidas sobre os Direitos da Criança que relaciona criança e informação. Em um cenário da Sociedade da Informação e em Rede (SOARES, 1996; CASTELLS, 2002), as tecnologias são artefatos que auxiliam no acesso e na utilização de qualquer informação que circula pelas redes telemáticas e com potencial de interações, disponíveis a todos os indivíduos que tenham acesso e competências para buscar, verificar, analisar e interpretar o que for divulgado, principalmente quando se refere a uma necessidade/demanda informacional deste cidadão.

A partir dessa perspectiva, este trabalho considera as crianças ${ }^{3}$ como cidadãs com necessidades informacionais que podem ser atendidas por meio do uso ético, crítico e criativo das informações com as quais têm contato a partir do uso das tecnologias da informação e da comunicação, contemplando o que se denomina de literacias ou alfabetização informacional

\footnotetext{
3 Neste trabalho, são consideradas crianças os cidadãos de até 12 anos de idade incompletos, conforme postula o Estatuto da Criança e do Adolescente (BRASIL, 1991).
}

Comun. \& Inf., Goiânia, GO, v. 20, n. 1, p. 42-56, jan./jun. 2017 
(AI). Parte-se ainda do pressuposto de que a geração da infância do século XXI desenvolve ou já nasce com competências para acessar e utilizar a internet (TAPSCOTT, 2010), o que poderia contribuir para uma formação de crianças bem informadas para a consolidação de uma sociedade democrática.

Identificar o uso que as crianças fazem da internet, ou melhor, das TIC é um dos passos necessários para se refletir sobre as potencialidades de uma formação adequada para ir além do acesso e pensar nas competências informacionais adquiridas e em desenvolvimento a partir do processo de educação formal e até não-formal. Nesse sentido, ao mapear os dados de acesso e uso das TIC pelas crianças e adolescentes brasileiros, o relatório "TIC Kids Online Brasil 2015”, do Comitê Gestor da Internet no Brasil (CGI, 2016), traz resultados para serem aprofundados e problematizados diante da proposta de alfabetização informacional da Unesco (WILSON et al., 2013). É este, portanto, o objetivo central deste estudo a fim de responder a problemática: como favorecer o uso da informação de e com qualidade a partir do acesso e uso infantil das TIC?

Metodologicamente, parte-se de uma pesquisa bibliográfica e documental sobre alfabetização informacional tendo como aporte central o documento da Unesco sobre o tema. Outro documento central para essa problematização é o relatório já citado do CGI, apresentado por meio de uma análise descritiva e de conteúdo quantitativo e qualitativo para que as interpretações e proposições pudessem articular os dados com os indicadores de AI. Cabe pontuar que esta proposta é apenas um dos olhares possíveis para os dados sobre as crianças e as TIC no Brasil. No entanto, julga-se pertinente esse recorte para que, a partir das correlações apresentadas, seja possível apontar caminhos aos atores sociais que participam da formação infantil nas diferentes instâncias da educação. Desse modo, acredita-se que as competências infantis diante da informação poderão ser valorizadas e aprimoradas para um exercício cidadão desde a infância.

\section{DIREITO À INFORMAÇÃO: COMPETÊNCIAS PARA ALÉM DO ACESSO}

Na sociedade contemporânea, a informação tem um papel central e definidor, uma vez que vai além do dado e da produção do conhecimento para estar presente nas relações entre os indivíduos, como diz Barreto (1994):

A informação sintoniza o mundo. Como onda ou partícula, participa na evolução e da revolução do homem em direção à sua história. Como elemento organizador, a informação referencia o homem ao seu destino [...] A informação, quando adequadamente assimilada, produz conhecimento, modifica o estoque mental de informações do indivíduo e traz benefícios ao

Comun. \& Inf., Goiânia, GO, v. 20, n. 1, p. 42-56, jan./jun. 2017 
seu desenvolvimento e ao desenvolvimento da sociedade em que ele vive (BARRETO,1994, p. 1).

Desse modo, a informação torna-se um elo entre o presente e futuro; o individual e o coletivo, possibilitando mediações que levam ao desenvolvimento do cidadão e à formação da sociedade. Garantir o direito a ela, então, é essencial para a sobrevivência do social e, quanto mais for produzida, mais exigirá qualidade e ética, de modo a fomentar as bases de uma sociedade informacional e democrática. Para tanto, é fundamental que os indivíduos estejam preparados e bem formados para o uso consciente e responsável das informações.

Ninguém consome 'informação' em si, e essa existe apenas em relação a uma capacidade de interpretação, seleção e reorganização que varia de um indivíduo a outro e de uma atividade a outra. $\mathrm{O}$ indivíduo nunca está só com uma máquina; ele está sempre em sociedade, em interação com outros problemas, outras lógicas, outras referências, que inelutavelmente interferem nas tarefas cognitivas. Enfim, não existe nenhuma relação entre o crescimento do volume de informação disponível e o crescimento de sua utilização. Quanto mais há informação, mais os filtros dos saberes e dos instrumentos culturais necessários a sua utilização são importantes (WOLTON, 2004, p. 375, grifo do autor).

Concordando com os apontamentos de Wolton (2004), percebe-se a necessidade de haver competências informacionais para um bom uso do que está à disposição, a partir de uma visão crítica sobre as fontes, os locais de acesso, os dados para, posteriormente, avaliar e interpretar diante de um contexto e, enfim, chegar à geração do conhecimento para atender a uma demanda informacional (BELLUZZO, 2007). Dentre as competências possíveis, a autora cita, ao considerar o cenário digital com a internet, "aprender a manipular símbolos, aprender a colaborar, aprender a usar a informação, aprender a resolver problemas e aprender a aprender" (BELLUZZO, 2007, p. 40).

Para o desenvolvimento dessas e demais competências e retomando o direito à informação, estabelecido na Declaração Universal dos Direitos Humanos ${ }^{4}$, a Unesco estabelece diretrizes para que haja uma alfabetização informacional (AI) a fim de garantir que os cidadãos se empoderem diante das informações e saibam se apropriar delas em prol do seu bem-estar e de todos ao seu entorno. $\mathrm{Na}$ proposta de um currículo para professores trabalharem com essa forma de alfabetização, alguns pontos se destacam para serem

\footnotetext{
4 "Toda pessoa tem direito à liberdade de opinião e expressão; este direito inclui a liberdade de, sem interferência, ter opiniões e de procurar, receber e transmitir informações e ideias por quaisquer meios e independentemente de fronteiras." (ONU, 1948, artigo 19).
}

Comun. \& Inf., Goiânia, GO, v. 20, n. 1, p. 42-56, jan./jun. 2017 
investigados e trabalhados - e podem se relacionar à proposta de AI desde a infância por meio das TIC como é demonstrado neste estudo -, a saber:

- Como a informação apresentada deve ser criticamente avaliada dentro de um contexto específico e amplo de sua produção; [...]

- como as mídias e outros provedores de informação poderiam contribuir racionalmente para promover as liberdades fundamentais e a aprendizagem continuada, especialmente à medida que elas relacionam como e por que os jovens acessam e usam as mídias e a informação hoje, e como eles selecionam e avaliam esses conteúdos;

- ética na mídia e na informação; [...]

- processos de acesso, busca e definição de necessidades informacionais;

- ferramentas de localização e busca de dados;

- como entender, organizar e avaliar informações, incluindo a confiabilidade das fontes;

- criação e apresentação de informações em diversos formatos; [...]

- uso de informações para a resolução de problemas e para a tomada de decisões na vida pessoal, econômica, social e política. Apesar de ser extremamente importante, este item representa uma extensão da $\mathrm{AMI}^{5}$ [...] (WILSON et al., 2013, p. 21).

Esses indicadores demonstram como a informação tem diferentes e complexas dimensões que precisam ser avaliadas por meio da aquisição das competências informacionais ou da AI. No entanto, antes desses aspectos, a primeira dimensão se refere ao acesso à mesma. Segundo Wilson (2013, p. 66), aceder às informações contribui para a democracia e para o desenvolvimento, sendo de responsabilidade dos provedores de informação possibilitar tal acesso, assegurando os direitos dos cidadãos. Na sequência, é necessário saber usá-la, ou seja, ter a competência em informação. Belluzzo (2007, p. 45) ressalta que esse "processo de busca de informação para a construção do conhecimento envolve o uso, interpretação e significados". Além disso, o usuário dessa informação "passa a ser um conhecedor de como o conhecimento está organizado, como buscar a informação, como usá-la de modo inteligente e como proceder ao processo de comunicação do conhecimento gerado" (BELLUZZO, 2007, p. $53)$.

Nesse sentido, chega-se à concepção de competência relacionada à autonomia dos próprios indivíduos (MIRANDA, 2004), tendo em visto que diante de uma mesma informação, dependendo da necessidade do cidadão e de seu contexto sociocultural, é cabível múltiplas interpretações que conduzem a tomadas de posição e ao exercício de cidadania.

\footnotetext{
5 Vale assinalar que o documento da Unesco tem como foco a alfabetização midiática e informacional (AMI). Para este estudo, adota-se apenas a AI de modo a contemplar primeiro o aspecto informacional da criança diante das TIC para, em propostas futuras, dialogar com a relação infantil e as mídias.
}

Comun. \& Inf., Goiânia, GO, v. 20, n. 1, p. 42-56, jan./jun. 2017 
Como essa autonomia também é necessária para se escolher o meio ao qual terá acesso à informação, Bruce (apud BELLUZZO, 2007) destaca que diante das tecnologias da informação e da comunicação precisa-se de uma competência baseada no aprendizado no uso das TIC e na necessidade de interagir com comunidades que se apoiam em plataformas tecnológicas.

Considerando, então, essa relação entre competência-informação-tecnologia, a análise aqui proposta se volta às crianças, que também são cidadãs nesta sociedade informacional e, como autores sinalizam, pertencem à primeira geração genuinamente digital.

\section{CRIANÇAS NA ERA DA INFORMAÇÃO E DA GERAÇÃO DIGITAL}

O autor Don Tapscott (2010) é um entusiasta da geração Internet, como ele mesmo nomeia os jovens que foram os primeiros a crescerem em um ambiente digital. Em seu estudo, destaca que as crianças dessa geração Internet serão jovens e adultos promissores, uma vez que estão imersos em uma cultura participativa e colaborativa, ao mesmo tempo em que “criticam, investigam, ridicularizam, fantasiam, procuram e informam" (TAPSCOTT, 2010, p. 33).

Essa visão otimista denota uma apropriação positiva das tecnologias e um uso coerente com o desenvolvimento infantil e as relações que vivenciam. Buckingham (2007), ao ressaltar os pontos de vista referentes a essa geração eletrônica, afirma que emerge uma visão de que as crianças possuem uma "alfabetização midiática" que não existe entre os adultos, ou seja, "as tecnologias de mídia, em especial, são consideradas capazes de oferecer às crianças novas oportunidades para a criatividade, a comunidade, a auto-realização" (BUCKINGHAM, 2007, p. 66). Nesse sentido, as crianças estariam se beneficiando com as tecnologias, o que estaria articulado ao seu aprendizado, mais colaborativo, e ao seu comportamento em sociedade.

Em contrapartida, há quem defende que as tecnologias isolam as crianças e podem afetar sua inocência, como postula Postman (1999) ao falar da relação com as mídias e problematizar a "morte da infância", uma vez que o excesso de informações ao qual as crianças estariam submetidas não agregaria em nada em sua evolução, cognitiva e comportamental, e não traria o reconhecimento de uma geração que tem contribuições sólidas a dar à sociedade. Outro autor dessa vertente, Bauerlein (apud TAPSCOTT, 2010), comenta que

Os jovens usuários da internet, sem dúvida, aprenderam mil coisas novas. Fazem uploads e downloads, navegam e batem papo virtualmente, postam e criam designs, mas não aprenderam a analisar um texto complexo, a

Comun. \& Inf., Goiânia, GO, v. 20, n. 1, p. 42-56, jan./jun. 2017 
armazenar fatos em sua cabeça, a compreender uma decisão política externa, a aprender com a história ou a escrever corretamente. Sem nunca terem reconhecido sua responsabilidade em relação ao passado, eles abriram uma fissura em nossos alicerces sociais, e isso fica claro em sua transição para a vida adulta e para a cidadania (BAUERLEIN, 2001 apud TAPSCOTT, 2010, p. 14).

Esse questionamento é fundamental ao se reconhecer o papel social das crianças, como cidadãos responsáveis, e ainda focar em aspectos relativos à educação, tendo em vista que as crianças, diante das tecnologias, estariam "intelectualmente" diferentes dos padrões de outras gerações. Diante dessas argumentações, as críticas e as preocupações relativas a essa geração digital, enunciadas brevemente neste trabalho, devem ser analisadas com atenção, assim como não se pode generalizar e propagar o otimismo inicial. Buckingham (2007) pondera tais análises, no entanto, corrobora com o fato de que a infância está em mudança, concomitantemente ao fato de as novas formas culturais, que emergem com as tecnologias, estarem associadas diretamente às crianças, como os games.

$\mathrm{O}$ autor ainda ressalta que, em meio às habilidades on-line das crianças, é importante considerar que há cenários de exclusão digital em muitos países e que o acesso à internet e às demais mídias é desigual. Além disso, não se pode ignorar que os processos de alfabetização, o que inclui o informacional e o midiático, são significativos para que as crianças saibam como utilizar tais informações e tecnologias.

$\mathrm{Na}$ internet, as crianças têm de procurar informações, em vez de simplesmente observá-las. Isso as obriga a desenvolver o raciocínio e habilidades investigativas. E muito mais - elas precisam se tornar críticas. Que sites são bons? Como posso discernir o que é real e o que é fictício tanto em uma fonte de dados quanto em um bate-papo virtual com o astro de um filme para adolescentes? (TAPSCOTT, 2010, p. 33).

Tendo como foco, portanto, essa questão informacional a partir do uso das TIC pelas crianças, algumas das respostas para essas indagações poderão se complementar com os questionamentos do relatório do Comitê Gestor da Internet no Brasil (CGI, 2016) sobre o uso da internet por crianças e adolescentes brasileiros para que, em seguida, seja possível articular os dados com a problematização da alfabetização informacional e a formação infantil no país relativas a essa questão.

\section{MAPEAMENTO “TIC KIDS ONLINE BRASIL 2015"}

A pesquisa "TIC Kids Online Brasil 2015" é uma iniciativa do Comitê Gestor de Internet do país, em sua quarta edição, visando "mapear possíveis riscos e oportunidade on- 
line, gerando indicadores sobre o acesso à Internet por crianças e adolescentes de 9 a 17 anos de idade, e sobre os usos que fazem dela" (CGI, 2016, p. 23-24). Realizada de novembro de 2015 a junho de 2016, o estudo contou com a participação de 3.068 crianças e jovens de 9 a 17 anos, entrevistados a respeito das seguintes temáticas: acesso e uso da Internet; atividades on-line; práticas de comunicação e redes sociais; habilidades para o uso crítico da rede; riscos e danos; mediação por pais ou responsáveis (CGI, 2016, p. 156). Cabe um adendo de que nessa pesquisa foram entrevistados pais e responsáveis pelas crianças a fim de compreender a relação que estabelecem com os filhos sobre o acesso e uso da internet. Embora os dados auxiliem na problematização aqui proposta, o foco da análise está nas respostas e consequentemente no comportamento on-line das crianças de 9 a 12 anos, uma vez que o objetivo deste estudo é debater a alfabetização informacional na infância. Considerando os dados relativos a essa faixa etária, observam-se os seguintes resultados ${ }^{6}$ :

- Acesso e uso: 63\% de 9 e 10 anos e 73\%, de 11 e 12 anos, são considerados usuários de Internet. $19 \%$ da primeira faixa etária e $26 \%$ da segunda acessam a internet pelo celular, sendo $80 \%$ em espaços coletivos das residências das crianças de até 10 anos e $68 \%$ em quartos para os de 11 e 12 anos. Já sobre o tipo de conexão, $62 \%$ da primeira faixa etária e $71 \%$ da segunda faixa têm acesso via Wi-Fi. 55\% das duas faixas acessam mais de uma vez por dia; $22 \%$ de 9 a 10 e $17 \%$ de 11 a 12 pelo menos uma vez por dia; e, $12 \%$ de 9 a 10 e $17 \%$ de 11 a 12 anos uma vez por semana.

- Atividades on-line: Observa-se que os usos estão relacionados à atividades de pesquisas e interação tanto com as ferramentas e aplicativos quanto com os demais usuários. Há um índice expressivo de crianças que jogam on-line, ouvem música e assistem a conteúdos. Os gráficos 1a e 1b trazem os resultados das atividades, conforme as faixas etárias.

\footnotetext{
6 Para este trabalho, estão sintetizados os dados mais pertinentes relativos ao acesso e uso das TIC e a problemática da alfabetização informacional. Em alguns tópicos, foram formulados gráficos com as respostas, de modo adaptado para o recorte da faixa etária, a fim de dar subsídios para as proposições apresentadas adiante.
}

Comun. \& Inf., Goiânia, GO, v. 20, n. 1, p. 42-56, jan./jun. 2017 
Gráfico 1a - Proporção de crianças e adolescentes, de 9 a 10 anos, por atividades realizadas no último mês

Fonte: Adaptado pelo autor (CGI, 2016, p. 377-381)
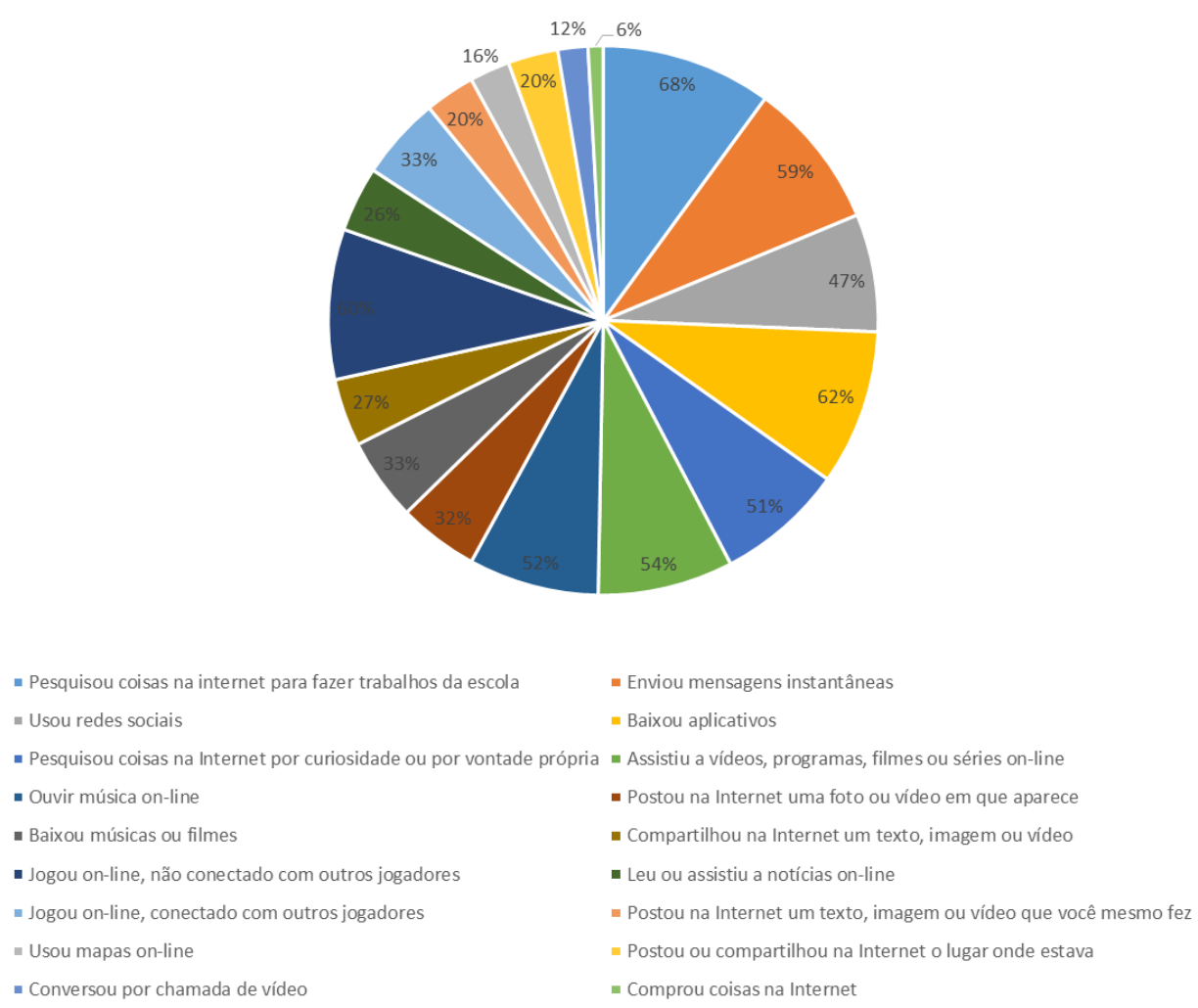

Gráfico 1b - Proporção de crianças e adolescentes, de 11 e 12 anos, por atividades realizadas na internet no último mês
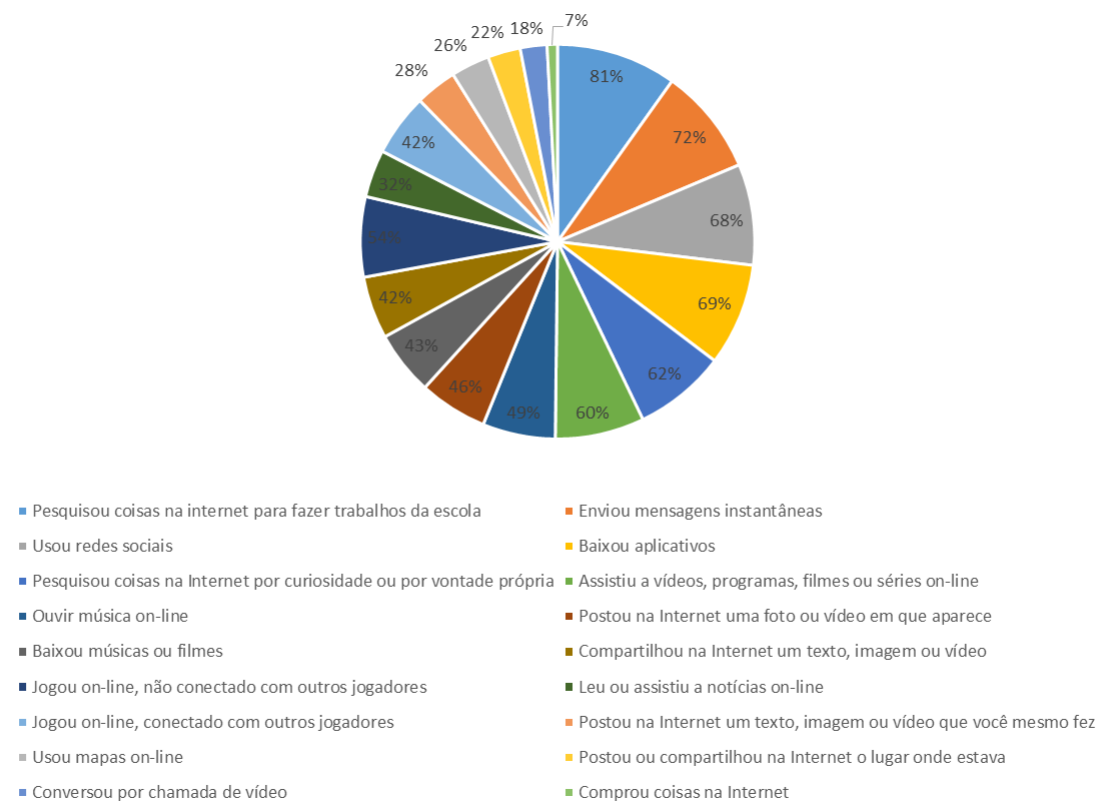

Fonte: Adaptado pelo autor (CGI, 2016, p. 377-381) 
- Práticas de comunicação e redes sociais: $63 \%$ de 9 a 10 anos e $79 \%$ de 11 a 12 anos têm perfil em rede social, em especial no Facebook e no WhatsApp, sendo referentes às duas faixas etárias -, respectivamente $35 \%$ e $51 \%$ perfis públicos e $31 \%$ e $32 \%$ perfis privados. Os gráficos $2 \mathrm{a}$ e $2 \mathrm{~b}$ apresentam os dados referentes às informações publicadas nas redes sociais digitais.

Gráfico 2a - Proporção de crianças e adolescentes, de 9 e 10 anos, por tipo de informações compartilhadas no perfil da rede social

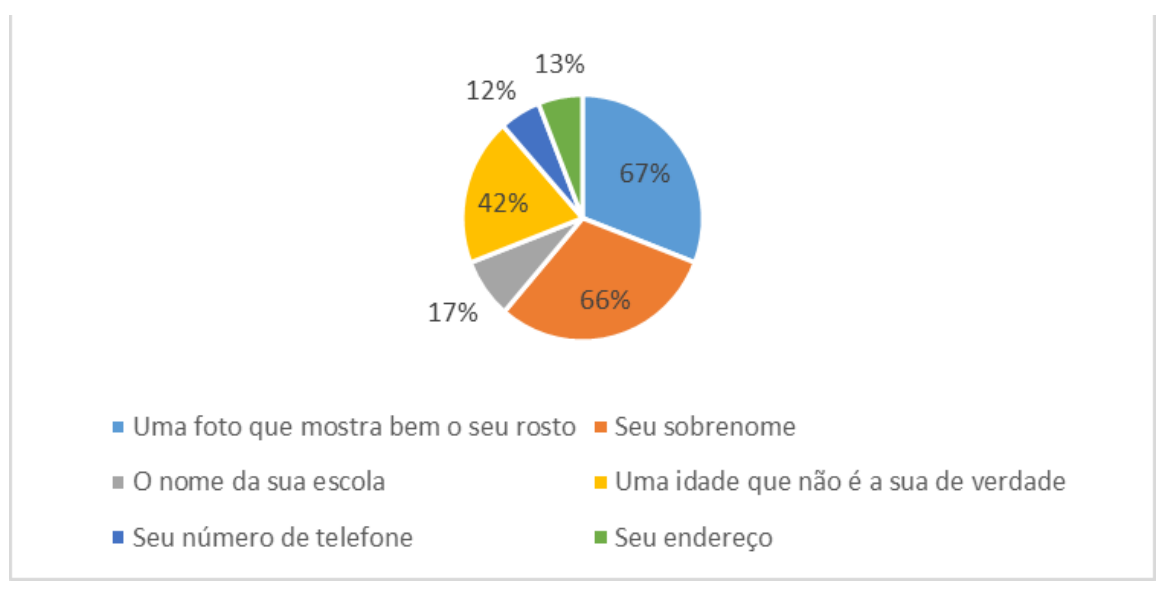

Fonte: Adaptado pelo autor (CGI, 2016, p. 388-389)

Gráfico 2b - Proporção de crianças e adolescentes, de 11 e 12 anos, por tipo de informações compartilhadas no perfil da rede social

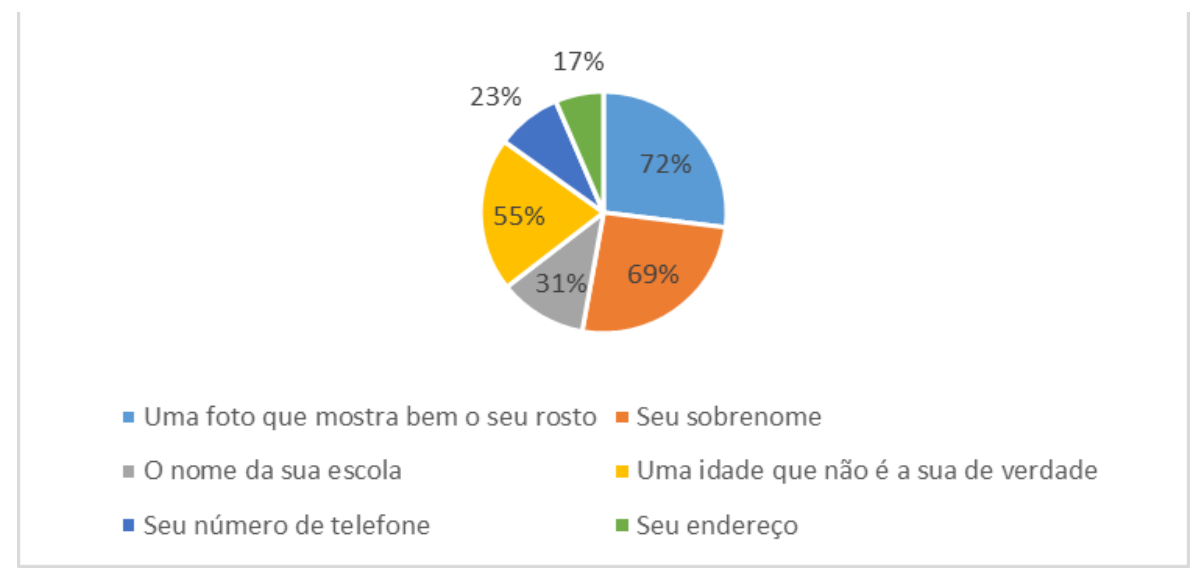

Fonte: Adaptado pelo autor (CGI, 2016, p. 388-389)

- Habilidades para o uso crítico da rede: $63 \%$ de 11 a 12 anos julgam saber mais que os pais como usar a Internet; $60 \%$ afirmam saber muitas coisas sobre como usar a internet e $75 \%$ concordam com o fato de que há muitas coisas boas para as crianças da mesma 
faixa etária (a respeito desses quesitos, a pesquisa não apresenta os dados referentes à população de 9 a 10 anos). Já sobre o que fazem na internet, os resultados estão no gráfico 3.

Gráfico 3 - Proporção de crianças e adolescentes, de 11 a 12 anos, por habilidades no uso da internet

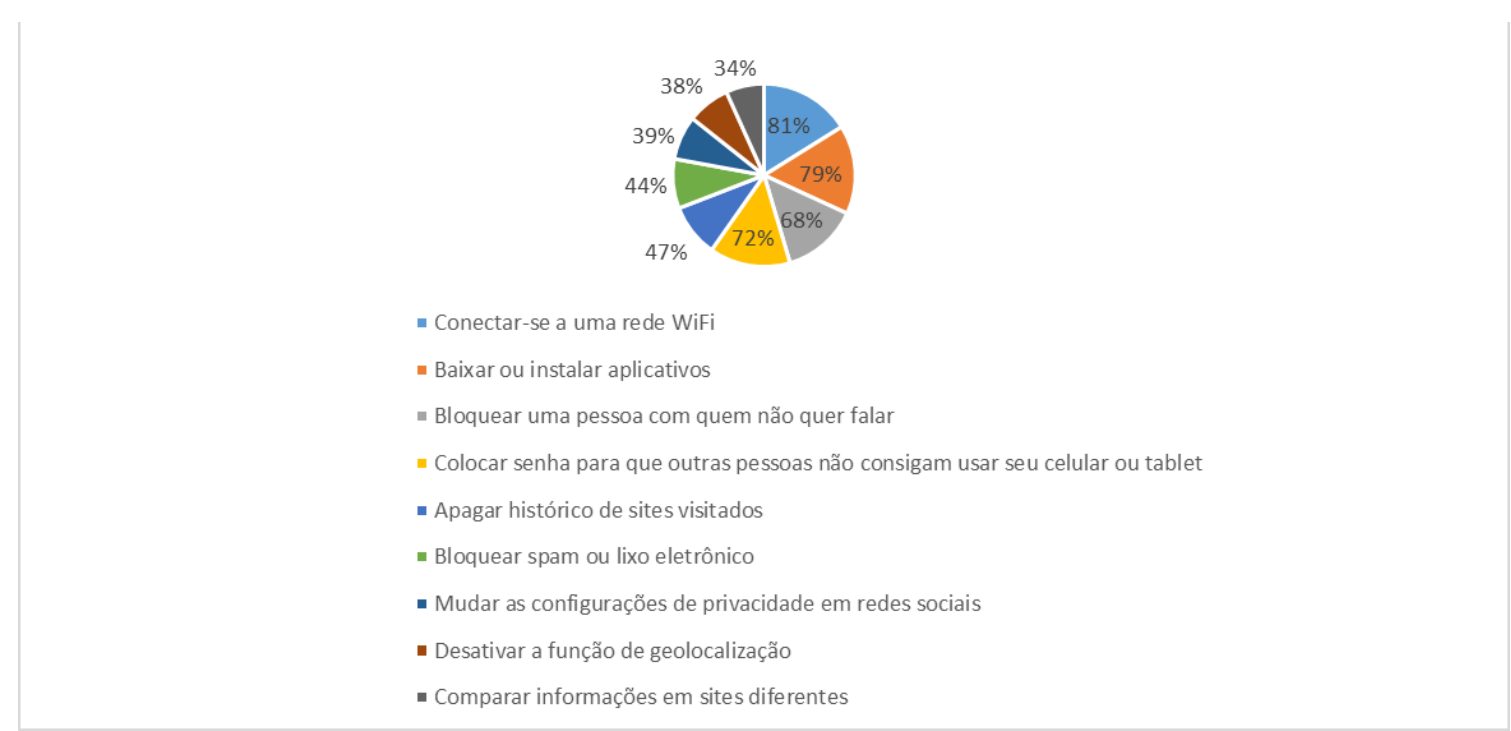

Fonte: Adaptado pelo autor (CGI, 2016, p. 393-395)

- $\quad$ Riscos e danos: $86 \%$ de 9 a 10 anos e $82 \%$ de 11 a 12 anos afirmaram que não agiram de forma ofensiva na internet. Já $88 \%$ e $86 \%$, respectivamente às faixas etárias, afirmam que não foram tratados de forma ofensiva na internet; $76 \%$ e $65 \%$, respectivamente às faixas etárias, não viram alguém ser discriminado na Internet e mais de $90 \%$ não se sentiram discriminados. O índice de crianças que vivenciaram situações de risco, como uso indevido de senhas e informações pessoais, é abaixo de 10\%. Já em relação a conteúdos com os quais tiveram contato, relacionados a formas de ficar magro, se machucar, suicídio e uso de drogas, $68 \%$ negaram que houve acesso a tais conteúdos.

\section{INFÂNCIA, ALFABETIZAÇÃO INFORMACIONAL E AS TIC}

A alfabetização informacional perpassa alguns elementos, elencados por Wilson (2013, p. 18), que se referem à definição e à articulação das necessidades informacionais, ao acesso, à organização, ao uso ético, à comunicação da informação e, por último, ao uso das TIC no processamento dessa informação. Ao relacionar tais aspectos com os resultados elencados do relatório "TIC Kids Online Brasil 2015”, a primeira questão é reconhecer qual a necessidade informacional das crianças. Há alguns indicativos que assinalam uma geração da infância com vínculo próximo às tecnologias, apropriando-se do mais recente artefato, o 
celular, e conectando-se diariamente à internet para realizar inúmeras atividades e desenvolver habilidades, que muitas vezes o adulto não compreende.

Essas crianças, de 9 a 12 anos, atrelam seu dia a dia ao convívio e ao relacionamento em rede, seja por meio de perfis em redes sociais ou na participação em comunidades para assistir a vídeos, trocar mensagens e, principalmente, jogar. Para essas atividades, são necessárias competências a fim de que as crianças executem-nas com êxito, divirtam-se e retomem tais tarefas que contribuem para seu aprendizado nos ambientes formais e não formais de ensino. Devido a isso, é importante que pais e professores se atentem para os resultados apresentados nos gráficos 1 e 3 para conhecer, em um primeiro momento, os usos potenciais da internet pelas crianças, assim, novas estratégias podem ser elaboradas nas escolas, nos lares e em demais instituições para auxiliá-las em um uso significativo das informações com quais lidam enquanto navegam nos ambientes digitais.

Tendo em vista que as crianças pesquisadas enunciaram uma expertise em relação à identificação do que as incomoda, na busca de segurança e do que as pode colocar em risco, ao mesmo tempo em que assumem um conhecimento sobre a rede e que isso é positivo, observa-se que há competências e necessidades informacionais em ação e que, se trabalhadas de modo a incentivar a criticidade e a criatividade infantis, vão aprimorar a relação das crianças com as informações, por meio do acesso e uso das TIC. É, nesse sentido, que pais e professores, além dos demais responsáveis pela educação e formação das crianças, deveriam assumir um papel mais ativo, não no sentido de controlar o que as crianças fazem na internet, mas de promover um aprendizado mais colaborativo e de confiança, reconhecendo que há “coisas boas” para essa geração na internet, como as próprias crianças já declaram.

Embora haja a visão otimista de Tapscott (2010) de que essa geração internet sabe acessar, selecionar, categorizar as informações, há ainda lacunas, como o fato de apenas 34\% de crianças de 11 e 12 anos compararem as informações em sites para verificar a veracidade e os índices expressivos de crianças que compartilham informações e/ou fotos pessoais on-line. O olhar crítico sobre o que leem e assistem on-line é fundamental para que não sejam tomadas atitudes, como as interações, via compartilhamentos, de conteúdos inverídicos e que podem propagar mensagens ofensivas, como de ódio, de uso de drogas, de defesa do estereotipo magro, as quais já estão disponíveis a elas. É, então, papel também dos atores que se responsabilizam pela formação das crianças incentivar a criticidade frente a tais mensagens e incentivar ações posteriores que sejam coerentes com valores éticos em prol do bem-estar de 
todos os indivíduos, como a sinalização, embora abaixo de $25 \%$, de identificação de ações de discriminação e ofensa na Internet.

Considerando os direitos de acesso à informação e de liberdade de expressão desde a infância, tornar-se competente, ou melhor, um alfabetizado informacional tem uma contribuição singular para essa geração, uma vez que Tapscott (2010) delega a essas crianças e jovens a responsabilidade, diante de um ativismo, de um comportamento cívico, de ajudar o planeta. Desse modo, as questões de segurança e privacidade infantil on-line são essenciais, e as crianças já demonstram um certo domínio tecnológico a partir de ferramentas para bloqueio e inserção de senhas, por isso que o autor defende a necessidade de dispor a elas ferramentas e oportunidades. Ter acesso às informações, saber utilizá-las e interpretá-las de modo crítico são parte desse processo. E aos adultos, cabe abrir espaço para se discutir tais informações junto às crianças para que o diálogo seja produtivo para a construção de um conhecimento transformador para a sociedade, como postula as diretrizes de AMI:

Eles [jovens] devem adquirir as habilidades básicas do pensamento crítico e da capacidade analítica, usando-as [informações] para sua autoexpressão com o objetivo de tornarem-se independentes como leitores, produtores, cidadãos bem informados e profissionais, e de participarem da governança e dos processos democráticos de suas sociedades (WILSON et al., 2013, p. $60)$.

Essa participação social já é vislumbrada na Internet devido ao fato das crianças e jovens estarem conectados à internet. A pesquisa "TIC Kids On-line 2015" mapeia os usos dos $80 \%$ dos usuários entre 9 e 17 anos que estão conectados. Um número muito expressivo que não corresponde às habilidades informacionais, já que os usos se diferem por região do País, classe econômica, grau de instrução e faixa etária. Diante da riqueza do mapeamento desses dados pelo CGI (2016) e as diretrizes de Alfabetização Midiática e Informacional da Unesco, reconhece-se a possibilidade de proporcionar às crianças um ambiente informacional na internet para e de uso crítico, conforme a síntese apresentada no quadro 1.

Quadro 1 - Síntese dos dados do CGI com as diretrizes de AI

\begin{tabular}{|c|c|}
\hline Alfabetização Informacional (Unesco) & Dados "TIC Kids Online Brasil 2015” \\
\hline Acesso às informações & $\begin{array}{c}\text { Crianças estão conectadas e têm acesso às } \\
\text { informações e exercem inúmeras atividades on-line. }\end{array}$ \\
\hline Organização das informações & $\begin{array}{c}\text { Não há indicativos da sistematização das } \\
\text { informações. No entanto, as crianças avaliam as } \\
\text { informações conforme seus interesses, do mesmo } \\
\text { modo que reconhecem riscos e ofensas on-line. }\end{array}$ \\
\hline Comunicação das informações & Crianças estão conectadas com outras crianças e \\
\hline
\end{tabular}




\begin{tabular}{|c|c|}
\hline Uso das TIC no processamento das informações & $\begin{array}{c}\text { fazem uso do recurso de compartilhamento de } \\
\text { informações, bem como sabem bloquear e comparar } \\
\text { fontes de informações. }\end{array}$ \\
\hline $\begin{array}{c}\text { Há inferências sobre a criticidade infantil diante dos } \\
\text { conteúdos on-line, mas não há indicativos de como a } \\
\text { TIC é utilizada para esse uso crítico. }\end{array}$ \\
\hline
\end{tabular}

Fonte: Elaborado pelo autor

\section{CONSIDERAÇÕES}

Falar em alfabetizar na infância é quase uma redundância, uma vez que há o consenso de que é nessa fase na qual se aprende a ler e a escrever. No entanto, quando se fala em alfabetização informacional, refere-se a um trabalho não apenas de domínio dos códigos de escrita e leitura, mas de criticidade para lidar com conteúdos e mensagens que atuam na formação de indivíduos e fazem valer os direitos dos cidadãos. Mais que ter acesso às informações, o uso é determinante para que estas ajudem na formação de uma sociedade democrática, na qual a ética no consumo, na produção e na socialização de informações seja o caminho percorrido independentemente da fase da vida e da geração.

Essa alfabetização informacional para uma geração da infância que mantém um contato tão próximo com as tecnologias da informação e da comunicação, em especial a internet, contribui para que as atividades e as habilidades on-line não sejam apenas instantâneas e velozes, mas sejam potencialidades que valorizem a autonomia infantil diante de todas as ações e exijam responsabilidades ética e cívica com o que se faz on-line. Exercitar-se na internet não deve ser encarado como um mero lazer, é um comprometimento com um aprendizado on-line que repercute nos espaços formais e não formais de ensino. Quem se relaciona com essa infância deve assumir também a responsabilidade de alfabetizar essas crianças para que possam desenvolver a criticidade e exercer sua cidadania.

Os resultados apresentados pela pesquisa “TIC Kids Online Brasil 2015” já acenam para olhares e sensibilidades infantis diante de situações que vivenciam na internet. Ao demonstrarem o contato das crianças com as informações, sejam as pessoais ou gerais como as que têm acesso em sites, vídeos e jogos, os dados suscitam problematizações a respeito da privacidade, do abuso em mensagens, do comportamento cético e crítico. Como uma das metas da AI é promover uma competência informacional para um uso ético, crítico e criativo das informações, as possibilidades que as tecnologias oferecem às crianças e aos demais cidadãos abrem perspectivas para um trabalho alfabetizador que possibilite muitas leituras e escritas significativas, analíticas, interpretativas e geradoras de um conhecimento para a consolidação de uma sociedade, na qual as crianças sejam vistas, ouvidas e reconhecidas

Comun. \& Inf., Goiânia, GO, v. 20, n. 1, p. 42-56, jan./jun. 2017 
desde o seu potencial para lidar com as informações, com as tecnologias e, em especial, com os outros, cujo encontro é possível on-line mas também na sociedade enquanto cidadãs de direitos.

\section{REFERÊNCIAS}

BARRETO, Aldo de Albuquerque. A questão da informação. 1994. Disponível em: $<$

http://bogliolo.eci.ufmg.br/downloads/BARRETO\%20A\%20Questao\%20da\%20Informacao.p df $>$. Acesso em: 16 jan. 2016.

BELLUZZO, Regina Célia Baptista. Construção de mapas: desenvolvendo competências em informação e comunicação. 2. ed. Bauru: Cá Entre Nós, 2007.

BRASIL. Decreto-lei no 8069, de 13 de julho de 1990. Dispõe sobre o estatuto da criança e do adolescente. Brasília: Coordenação de Publicações, 1991.

BUCKINGHAM, David. Crescer na era das mídias eletrônicas. Tradução Gilka Girardello, Isabel Orofino. São Paulo: Edições Loyola, 2007.

CASTELLS, Manuel. A sociedade em rede: a era da informação: economia, sociedade e cultura. 6. ed. São Paulo: Paz e Terra, 2002. 1 v.

CGI. TIC Kids online Brasil 2015: Pesquisa sobre o uso da internet por crianças e adolescentes no Brasil. São Paulo: Comitê Gestor de Internet no Brasil, 2016.

MIRANDA, Silvânia Vieira. Identificando competências informacionais. Ciência da Informação, Brasília, v. 33, n. 2, p. 112- 122, maio/ago. 2004.

ONU. Convenção dos Direitos da Criança. UNICEF, 1989.

Declaração Universal dos Diretos Humanos. 10 de dezembro de 1948.

POTSMAN, Neil. O desaparecimento da infância. Tradução Suzana Menescal de Alencar Carvalho, José Laurenio de Melo. Rio de Janeiro: Graphia, 1999.

SOARES, Ismar de Oliveira. Sociedade da Informação ou da comunicação? São Paulo: Cidade Nova, 1996.

TAPSCOTT, Dan. A hora da geração digital: como os jovens que cresceram usando a internet estão mudando tudo, das empresas aos governos. Tradução Marcello Lino. Rio de Janeiro: Agir Negócios, 2010.

WILSON, Carolyn et al. Alfabetização Midiática e informacional: currículo para formação de professores. Tradução Dermeval de Sena Aires Júnior. Brasília: Unesco, UFTM, 2013.

WOLTON, Dominique. Pensar a comunicação. Tradução Zélia Leal Adghiri. Brasília: Editora UnB, 2004. 